Department of Business Administration

UZH Business Working Paper Series

(ISSN 2296-0422)

Working Paper No. 305

Corporate Responsibility as Myth and Ceremony:

Bad, but Not for Good

Patrick Haack

Dirk Martignoni

Dennis Schoeneborn

October 72013

Work in progress: Please do not cite without the authors' permission

University of Zurich, Plattenstrasse 14, CH-8053 Zurich, http://www.business.uzh.ch/forschung/wps.html 
UZH Business Working Paper Series

\section{Contact Details}

\section{Patrick Haack}

University of Zurich, Switzerland

patrick.haack@uzh.ch

\section{Dirk Martignoni}

University of Zurich, Switzerland

dirk.martignoni@uzh.ch

\section{Dennis Schoeneborn}

University of Zurich, Switzerland

dennis.schoeneborn@uzh.ch

This paper has been presented at the European Group of Organisational Studies (EGOS) Colloquium, July 4-6, 2012, Helsinki/Finland. We thank Katja Rost, Andreas Scherer, and David Seidl for their valuable feedback regarding earlier versions. We furthermore gratefully acknowledge the financial support by the Swiss National Science Foundation (SNSF; grant no. 100018_129995). 


\title{
CORPORATE RESPONSIBILITY AS MYTH AND CEREMONY: \\ BAD, BUT NOT FOR GOOD
}

\begin{abstract}
Organizations adopt corporate responsibility (CR) policies often ceremonially, meaning that policy adoption is not substantive and lacks alignment with actual practice. Prior research in institutional theory has largely assumed as static view of adoption and suggests that a situation of opacity (i.e. the difficulty or impossibility of evaluation) stabilizes ceremonial adoption and thus impedes substantive adoption. This paper offers a dynamic view of adoption sequences and re-examines the role of opacity in promoting substantive adoption among multiple organizations within a given field or industry. Using a three-state Markov chain model, we specify the boundary conditions under which initial opacity paired with a change towards transparency (i.e. the relative ease or possibility of evaluation) maximizes the overall number of substantive adoptions. Our findings suggest that the institutionalization of CR-related policies can be advanced by leaving organizations significant leeway and autonomy in their adoption decision. In turn, institutionalization may be hampered by initial requests for transparency and organizational accountability. We discuss implications for (1) efforts to institutionalize CR as a global governance mechanism and (2) the institutional theory concepts of decoupling and (re-)coupling.
\end{abstract}

\section{KEYWORDS}

corporate responsibility, decoupling, diffusion, implementation, institutional theory, selfreinforcing process 


\section{CORPORATE RESPONSIBILITY AS MYTH AND CEREMONY: \\ BAD, BUT NOT FOR GOOD}

The last decade has witnessed the emergence of a plethora of principle-based initiatives, certification, reporting and accountability frameworks, and other formalized modes of industry self- or co-regulation in the realm of human rights, social rights, and environmental protection (Gilbert, Rasche, \& Waddock, 2011). Notwithstanding the prevalence and rising significance of these corporate responsibility (CR) initiatives, several researchers (e.g. Aravind \& Christmann, 2011; Behnam \& MacLean, 2011) have found that CR polices are often implemented superficially to produce a 'green' and socially responsible image that does not affect organizational core activities (Laufer, 2003). Scholars in institutional theory likewise argue that policy-practice decoupling, i.e. the pretended yet unrealized adherence to societal expectations (Meyer \& Rowan, 1977), is particularly pertinent in the realm of CR (Boiral, 2007; Jamali, 2010). Whereas institutionalists view decoupling as beneficial to the organization as it enhances legitimacy and internal coordination (Brunsson, 1989; Meyer \& Rowan, 1977), from a societal point of view both institutionalists and CR researchers regard decoupling as undesirable as exacerbating the organizational embedding and institutionalization of CR (Behnam \& MacLean, 2011).

Both CR researchers and institutionalists suggest that opacity (a situation characterized by the difficulty or impossibility of evaluation) amounts to an important antecedent of decoupling. The central role of opacity in the stabilization of decoupling is typified in Meyer and Rowan's “logic of confidence and good faith” (1977: 357) where constituents abstain from evaluation and control, support the ceremonial adoption of a policy, confer legitimacy, and thus ensure the stability of the organization. Transparency (referring to the possibility or relative ease of evaluation), in turn, is characterized by a situation where evaluators engage in 
social control and get to the bottom of the organization's essence and activities. Transparency may thus lead to the disapproval of the organization, threaten its legitimacy and stability, and pressure the organization to justify the failure to substantively adopt a CR practice, i.e. to carry out an adoption that is characterized by a close alignment between self-presentation and actual conduct (Christmann \& Taylor, 2006). Thus, transparency may eventually lead to accountability, where adopters are urged to "give an account of the rationale of [their] behavior to significant others when called upon” (Zyglidopoulos \& Fleming, 2011: 4). In short, both CR researchers and institutional theorists ("transparentists" in the following) embrace the virtues of transparency, criticize opacity, and suggest that "raising the bar”, i.e. introducing stricter accountability and reporting requirements will advance the organizational embedding of CR (Gilbert et al., 2011).

Yet, notwithstanding the important and enlightening work of transparentists, there is tentative evidence that opacity can be constitutive of the institutionalization of CR. For instance, several scholars have raised conceptual and empirical attention to the phenomenon of coupling processes, and explored the transitory nature of decoupling within organizations (Hallett, 2010; Tilcsik, 2010; for an overview see Bromley \& Powell, 2012). These studies suggest that a decoupled structure is unlikely to maintain its symbolic power without organizational consequences (Scott, 2008; Tolbert \& Zucker, 1996). Indeed, a state of opacity and merely 'talking the walk' (to engage in window-dressing) allows decision-makers to experiment with, make sense of, and gradually internalize a novel practice and thus contribute to the demise of organizational hypocrisy (Weick, 1995: 183; see also March, 1995: 263). Thus, in a situation of opacity, organizations may start off with the practice of decoupling, but eventually engage in the practice of tighter coupling (Scott, 2008), for instance, by putting considerable effort in the integration of formal policies in actual business structures and processes-despite or rather because of a lack of social control and evaluation. In view of 
that, even the most hypocritical adoption of a CR policy can prove instable and yield longterm institutional consequences (Haack, Schoeneborn, \& Wickert, 2012). Hence, a core notion in the opacitist perspective asserts that intransparency and the non-disclosure of practice implementation furthers the institutionalization of $\mathrm{CR}$, a predication that is diametrically opposed to the writings of transparentists.

In this paper, we shall argue that both the transparentist and the "opacitist" perspective are theoretically incomplete as based on a binary and largely static conception of social reality. Specifically, the possibility of sequencing and endogeneity effects, as well as of selfreinforcing processes (see, e.g., Sydow, Schreyoegg \& Koch, 2009), is neglected. As elaborated further below, this deficiency poses serious challenges to the development of a more robust and comprehensive theorizing of how CR takes effect and persist in organizational contexts. More generally, although management scholars have explored postadoption dynamics within organizations (Ansari, Fiss, \& Zajac, 2010), as well as interorganizational variation in practice implementation (Kennedy \& Fiss, 2009; Lounsbury, 2001), so far, the institutional theory literature lacks an understanding under which conditions policies are realized systematically and effectively across a majority of organizations within a given field or industry. As Sydow and his colleagues (2009: 698) argue: "While neoinstitutional theory elucidates imprinting and stabilizing processes and, in particular, sensitizes us to the relevance of symbolic-normative contexts [...], it does not address the systemic logic of an escalating underpinning of an action pattern or path.” In line with Sydow and his colleagues we posit that extant institutional theory conceptions of the diffusion and implementation of CR initiatives would benefit from a dynamic theorization of evaluation and adoption, which explicitly takes into account notions of path dependence and self-reinforcing processes. 
Specifically, we seek to enhance our understanding about the contextual circumstances under which transparency/opacity advances not only "breadth", i.e. maximizes the number of ceremonial adoptions within an industry, but also “depth”, that is, a majority of organizations and organizational members actually conceiving, implementing, and thus 'living' and substantively adopting the standard. We model adoptions patterns by means of a discretetime, discrete-state Markov chain process, a frequently applied modeling technique in organization science (e.g., Pentland, Hærem, \& Hillison, 2010). Markov chain models allow us to compute field-level outcomes based on a random process involving initial adoptions states (non-adoption, ceremonial adoption, substantive adoption) and transition probabilities for each state at each point in time (Abbott, 1990). By means of the Markov methodology, we shall explore the boundary conditions under which the process sequence "initial opacity followed by transparency" maximizes the number of substantive adoptions within a given field (compared to all other possible process sequences). This approach helps advance greater conceptual clarity and a more robust theorizing of institutionalization and self-reinforcing processes in the realm of CR (see Vergne \& Durand, 2010).

Our paper's contribution is twofold. First, our study prompts the rethinking of decoupling and "greenwash" as detrimental to the institutionalization of CR as a global governance mechanism, as currently conceived in the mainstream CR literature (Aravind \& Christmann, 2011; Behnam \& MacLean, 2011; Delmas \& Montes-Sancho, 2011). Second, we integrate institutional theory (Scott, 2008) and the path dependence concept (Sydow et al., 2009; Vergne \& Durand, 2010) by adopting an explicit proccessual perspective which allows to temporally separate theoretical incompatibilities among transparentists and opacitists (see Okhuysen \& Bonardi, 2011; Poole and van de Ven, 1989). Specifically, by modeling process sequences through Markov chains, we elucidate how substantive adopters enforce 
transparency, what renders decoupling infeasible, creating a path characterized by coupling processes and growing number of substantive adoptions (lock-in).

We structure this paper as follows. Subsequent to this introduction, we review both the opacitist and transparentist perspective. Next, we motivate the application of Markov chain models, and describe the outcomes of a baseline illustration. We then explore the boundary conditions under which specific process patterns of opacity vs. transparency enable the growth of substantive adoptions. We furthermore specify the consequences of the variation and endogenization of threshold values (points in time where a situation switches from opacity to transparency or vice versa). We conclude by discussing implications for the decoupling concept and efforts to institutionalize CR as a global governance mechanism.

\section{TWO IDEAL-TYPE PATHS TO CR: TRANSPARENCY VS. OPACITY}

Which factors explain the attainment of depth, i.e. a rising share of substantive adoptions and ensuing institutionalization of CR? Focusing on the pivotal role of social evaluation, there are (at least) two answers to this important question. The first response reflects the literature's dominant assumption that realizing depth necessitates a situation of transparency as it coerces organizations to abandon policy-practice decoupling, i.e. to “walk the talk' and align rhetoric with action (Aravind \& Christmann, 2011; Behnam \& MacLean, 2011). The second response starts from the opposite conjecture in that it suggests that opacity is a necessary (albeit insufficient) condition for substantial adoption. Contrasting transparency with opacity reveals the need for a theoretical integration and temporal separation of the two perspectives which explicitly considers the procedural nature of adoption (Poole \& van de Ven, 1989).

\section{Transparency}

The observation that CR often proves to be merely window-dressing signals that organizations engage in decoupling (Meyer \& Rowan; 1977; Weick, 1976). From an institutional theory point of view, the decoupling of policy and practice equals ceremonial 
adoption and represents a strategy of organizations to maintain legitimacy when responding to contradictory institutional demands (Boxenbaum \& Jonsson, 2008; Bromley \& Powell, 2012). Consequently, researchers have paid attention to whether organizations actually implement CR policies (Aravind \& Christmann, 2011; Boiral, 2007; Jamali, 2010; Long \& Discroll, 2008) and examined the various antecedents and consequences of decoupling (Behnam \& MacLean, 2011; Christmann \& Taylor, 2006). Findings suggest that patterns of widespread diffusion of a CR policy cannot be equated with the policy's embedding in organizational activities; For instance, low-entry barriers for adopting policies and lax enforcement mechanisms and reporting requirements have been found to encourage shirking and freeriding (King \& Lenox, 2000), and to institutionalize unethical and opportunistic behavior within organizations (MacLean \& Behnam, 2010). As a consequence, scholars have emphasized the need for increased transparency to hold adopters accountable and enforce the implementation of CR policies (Behnam \& MacLean, 2011).

The call for transparency constitutes a hallmark of "transparentists", a set of scholars in CR research (Gilbert et al., 2011) and institutional theory (Boiral, 2007) who suggest that monitoring and control significantly advances the substantive adoption of CR. Transparentists stipulate high entry barriers, strict reporting and accountability requirements, and call for sanctions, such as “delisting” in case adopters are non-compliant (Aravind \& Christmann, 2011). They reason that the inspection of actual practice implementation helps promote CR and ethical conduct in organizations, reduce the propensity of free riding and adverse selection, and thus speed up a CR initiative's development towards depth (Behnam \& MacLean, 2011; MacLean \& Behnam, 2010). Indeed, in the realm of CR, the assumption that both internal and external constituents operate under the "logic of confidence and good faith" (Meyer \& Rowan, 1977: 357) that allows organizations to persist in a decoupled manner seems inapplicable. That is, the proliferation of CR policies is accompanied by evaluation 
where demands for transparency and accountability render the perpetuation of organizational hypocrisy often impossible — very much in contrast to Meyer and Rowan's (1977) baseline assumption of omnipresent “confidence” and “good faith”. Instead, we often discern cynicism on part of internal constituents such as employees who are unwilling to engage in "Goffmanesque backstage/frontstage activities", that is, they struggle to fully support ceremonial behavior (Tolbert \& Zucker, 1996, p. 179). Likewise, external constituents such as non-governmental organizations (NGOs) are skeptical of the genuineness of rhetorical commitments, and symbolically sanction decoupling through 'naming and shaming' campaigns (den Hond \& de Bakker, 2007). In sum, transparentists reason that in view of public scrutiny and rising demands for accountability, decoupling is not a viable long-term option for adopters of CR-related policies and hypocritical organizations are inevitably pressured towards substantive adoption. It follows that the fastest way towards depth predisposes the promotion of transparency, and, where necessary, the expeditious and forceful condemnation of ceremonial adoption and decoupling.

\section{Opacity}

Second, less recognized and consistent than the transparentist perspective, proponents of the opacitist perspective argue that low entry barriers, lax reporting requirements, and lacking accountability are actually conducive to depth, i.e. the spread of substantive adoptions. For instance, at the organizational level of analysis, opacitists link control systems to organizational failure, and emphasize that the application of sanctions and control often has counterproductive effects on intrinsic motivation and trust in organizational contexts (for an overview, see Tenbrunsel \& Messick, 1999). Weick (1995: 183) eminently summarizes the rationale of “opacitism”: 
If [the mangers] are forced to walk the talk, this may heighten accountability, but it is also likely to heighten caution and inertia and reduce risk taking and innovation. This outcome occurs not just because people are scared. It occurs because people who are forced to walk the talk prematurely often forgo exploration and walk on behalf of words that they barely understand. Because things that are poorly understood are things that tend to be seen as uncontrollable, they seem like threats rather than opportunities. Innovation shuts down.

Hence, at the organizational level, ceremonial adoption is believed to help adopters to understand the need to honor their promises and thoroughly implement CR policies. At the field level, a rise of ceremonial adoptions may enhance the stabilization and institutionalization of $\mathrm{CR}$ as not all norm violations (e.g. lacking implementation or hypocritical behavior more generally) become immediately visible (Diekmann, Przepiorka, \& Rauhut, 2011). This helps a CR-related policy achieve a critical mass of adoptions that brings about acceptance, comprehensibility, and taken-for-grantedness of the policy's very essence and objectives. It follows that the fastest way towards depth is to endow organizations with freedom and autonomy in the decision whether and when to implement a policy. In other words, from the viewpoint of opacitists one must not unconditionally sanction organizations for hypocrisy and "greenwashing”. Instead, one is well advised to tolerate decoupling as it enables organizations and whole industries to "talk the walk", i.e. to explore, embrace and eventually enact ethical prescriptions (March, 1995; Weick, 1995). Opacitists thus imply that decoupling may merely amount to a transitory phenomenon and clarify that a formal adoption decision may pave the way towards substantive adoption within an organization, i.e. the tighter coupling of policy and actual practice (Christensen, Morsing, \& Thyssen, 2011; Hallett, 2010; Scott, 2008; Tilcsik, 2010; Tolbert \& Zucker, 1996). For the organizational level, this notion is evidenced by the concept of "moral entrapment" as developed in a recent case study of Haack and colleagues (2012) which analyzed the dissemination of a CR initiative in the field of international project finance. The authors find that commercial banks that formally adopted a CR policy reacted to civil society criticism by publically promising 
increased implementation efforts. Hence, by committing themselves to ceremonial adoption and a good cause, banks became "morally entrapped" and inevitably moved towards tighter coupling. Similarly, Christensen and his colleagues (2011) suggest that “aspirational talk”, i.e. the rhetorical pledge to reduce the gap between actual and projected reality, eventually leads CR to take deeper roots within organizations. Thus, although organizations may require a period of “incubation” until formally adopted practices materialize in activity (Røvik, 2011), the interaction with alternative logics in heterogeneous contexts induces tight coupling of policy and practice.

\section{Deficiencies of transparentism and opacitism}

Overall, there is a major problem with the two ideal-type views of how to institutionalize CR. Both perspectives argue that either transparency or opacity enhances the likelihood of substantive adoption. Hence, if reckoned in isolation, they represent a binary description of social reality which assumes a unidirectional and static relationship between the possibility of evaluation (transparency/opacity) and type and number of practice adoptions (ceremonial/substantive). The possibility that evaluation and adoption are mutually constitutive and are subject to self-reinforcing processes is neglected. In our view, the inattention to the social dynamics of practice adoption amounts to a major deficiency of both the transparentist and opacitist perspective as they leave unexplored the very processes that account for variance in institutional outcomes (Suddaby \& Greenwood, 2009; Schneiberg \& Clemens, 2006), and lack insight on how to best promote the institutionalization of CR.

In this paper, we contend that transparency/opacity can be endogenous to the type and number of practice adoption, and vice-versa. That is, a field-wide increase of a certain type of adoption may not only increase the likelihood of subsequent adoptions of that type at the level of the single organization (the classical notion of isomorphism and bandwagon effects in the case of ceremonial adoption), but also affect evaluators' demands for social control. Changes 
in evaluation (e.g. a swap from opacity to transparency), in turn, alter the propensity of ceremonial and substantive adoption. For instance, in a situation of ubiquitous ceremonial adoption (triggered, for instance, by low entry barriers and lacking demands for transparency), both substantive and ceremonial adopters are 'tarred with the same brush' as evaluators are confronted with a situation of opacity and cannot discern differences in adoptions. Constituents then generalize (erroneously) from single instances of ceremonial adoption to the whole population of adoptions (Jonsson, Greve, \& Fujiwara-Greve, 2009). It follows that both ceremonial and substantive adopters loose social approval and are discredited in the eyes of constituents. Hence, substantive adopters have an interest to differentiate themselves from "laggards", i.e. the ceremonial adopters, and start enforcing transparency, for instance by setting up organizational bodies that monitor compliance with CR policies. As a result, und fully in line with the arguments of transparentists, more and more organizations are going to switch from ceremonial to substantive adoption, and fuel a self-reinforcing process that ultimately leads to the institutionalization of CR. Yet, setting in motion this process has been dependent on an initial situation of opacity, as it allowed ceremonial adoptions to reach “critical mass” (Barnett \& King, 2008). Hence, although contradictory when viewed in isolation, both the arguments of transparentist and opacitists are valid, a paradox we solve in the temporal dimension by applying a dynamic perspective that allows building an internally consistent theory of practice adoption (Poole \& van de Ven, 1989; Tolbert \& Zucker, 1996).

A recent empirical study lends credence to the conjecture that initial opacity if followed by transparency paves, or at least facilitates the way towards depth. Haack and his colleagues (2012) suggest that lax requirements, low entry barriers, and a early vote of confidence on part of civil society (reflecting a situation of minimized evaluation) eased formal adoption and therefore has been largely conducive to the diffusion of a CR policy in 
the realm of international project finance, the so-called "Equator Principles". Yet, over time, due to civil society criticism of the initiative's lacking impact, a small but rising number of substantive adopters saw threatened the stability and legitimacy of the whole initiative and pushed the field of project finance towards greater transparency and accountability. This has been achieved, for instance, by establishing a governance body overseeing annual reporting of implementation efforts, differentiating between advanced and associated (i.e. less advanced) adopters, and involving external stakeholders (e.g. civil society actors) in the formulation of strategic change processes.

In sum, the role of transparency/opacity in promoting substantive adoptions has not been adequately theorized in the institutional theory literature as being based on a static and one-directional account of causal relationships, not taking into account sequence and endogeneity effects. Specifically, we lack an understanding of the boundary conditions under which transparency and ensuing ceremonial adoption advances the growth of substantive adoptions in a given field, i.e., is constitutive of depth and the institutionalization of CR. We explore this question by formally modeling adoption sequences and process outcomes by means of a Markov chain model.

\section{MARKOV CHAIN MODELS AS A THEORY DEVELOPMENT TOOL: ASSUMPTIONS, SPECIFICATIONS, AND ILLUSTRATION}

In order to develop a better understanding and develop novel theory on the role of transparency vs. opacity in promoting substantive adoption we employ a simple Markov chain model (e.g., Pentland et al., 2010). Markov models have proven useful for studying a wide range of organizational phenomena, spanning analyses of the contingency of career paths on individual-level characteristics (March \& March, 1977) to the examination of the variety of sequential patterns within organizational routines (Pentland, 2003; Pentland et al., 2010). Markov chain models are probabilistic models that allow representing a process as it moves 
from state to state through time and predicting an end state on the basis of the initial states and transition probabilities at each point in time (Abbott, 1990). Hence, given that the current state in itself is dependent from the system's historicity and earlier events that occurred somewhat randomly, Markov models are particularly suited to study the dynamics of pathdependent phenomena (Vergne \& Durand, 2010).

Furthermore, the Markov methodology is particularly apt to tackle two major challenges when studying the role of transparency/opacity in adoption processes: First, empirically, the depth dimension (how thoroughly or "substantively" is a practice integrated within a majority of organizations) is difficult to uncover as it requires the longitudinal and careful investigation of both degree and quality of practice implementation, typically in form of ethnographic studies at several single case organizations. Clearly, such a detailed understanding is difficult to achieve at a field level given ubiquitous time and budget constraints in social science research. Also, organizational facades, ceremonial behavior, and social desirability biases defy easy measurements because of the incapability and/or unwillingness of organizations to disclose information about internal CR efforts. Given these impediments, previous studies have focused either on policy diffusion at the field level (e.g., Abrahamson \& Fairchild, 1999) or implementation quality within single organizations (e.g., Boiral, 2007; Humphreys \& Brown, 2008). Second, conceptually, although there is a growing body of theoretical research on (re-) coupling processes (Hallett, 2010; Tilcsik, 2010), we lack a comprehensive and fully dynamic conception of theoretically relevant transitions between different adoption states.

Formal modeling based on Markov chains allows for addressing both deficiencies: First, given that Markov models create their own 'virtual' data and allow computing an infinite number of counterfactual scenarios, time and budget requirements are reduced and problems of secrecy and distrust do not accrue. Second, Markov models help to uncover how 
simple adoption patterns scale up towards institutional structures and outcomes, therefore offering a viable method for theory development on sequencing and endogeneity effects in the institutionalization of CR (see Langley, 1999), in a path-dependent and self-reinforcing manner (Vergne \& Durand, 2010).

In the context of our study, we are particularly interested in how the possibility of evaluation (transparency/opacity) may affect the extent to which organizations adopt a CR practice substantively. We model adoption sequences as a simple, homogenous, and stationary Markov process and distinguish between three different organizational states: nonadoption (state 1), ceremonial adoption (state 2), and substantive adoption (state 3). In each period, an organization may or may not move from its current state to another state with a given probability. The transition between two states is a stochastic process; the probability that an organization moves from, for example, state "non-adoption" to state "substantive adoption" is given by $p_{13}$; the probability that an organization moves from "non-adoption" to “ceremonial adaption" is given by $p_{12}$. It follows that the probability of remaining in a state of “non-adoption" is defined as $p_{11}=1-p_{12}-p_{13}$. For example, if an organization resides in the state "non-adoption" and the probability to remain in that state or to move to ceremonial adoption amount to 70 and 20 percent, respectively, then, by definition, the probability of substantive adoption equals 10 percent. Importantly, if the initial probability state distribution is given (e.g., organizations are either non-adopters or ceremonial adopters with equal probabilities), a Markov chain model allows computing the corresponding probability state distributions for all subsequent periods. Given that the probability of an organization to adopt substantively equals the share of substantive adoptions among all adoptions, Markov models allow us to infer the overall number of substantive adoptions at each point of time.

We represent a situation (“evaluation regime” or simply "regime”) of transparency through a specific transition matrix which defines the set of all states and all possible 
transition possibilities. In turn, a regime of opacity is defined by a transition matrix with a different set of transitions probabilities. We assume that a regime change occurs between two time periods and is captured by a change in the respective transition matrix. Figure 1 provides a high-level overview of the three-state Markov chain model we apply in this paper, whereas NA stands for “non-adoption”, CA for “ceremonial adoption, and SA for "substantive adoption”.

\section{Figure 1: Illustration Markov Chain Model}

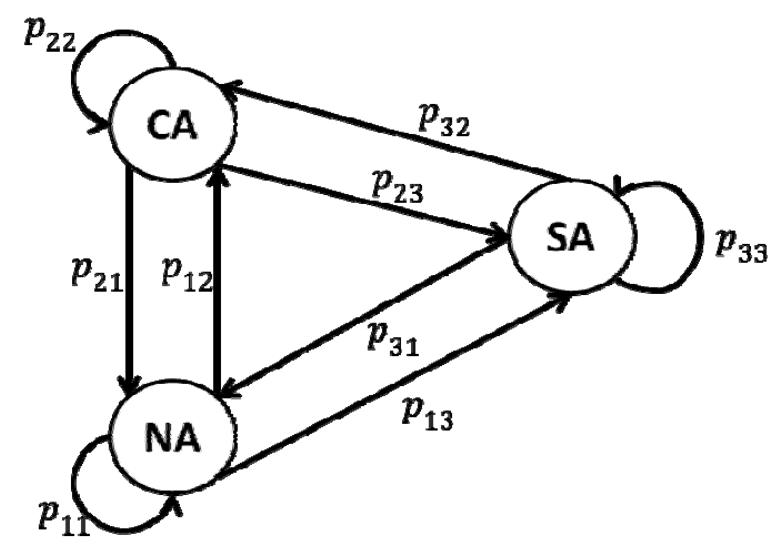

The distribution of states after $T$ periods (i.e. the number of periods under the regime of transparency) is given by $x(t)=x(0) P^{T}$ with the initial distribution of states given by $\mathrm{x}(0)$ and the transition matrix $\mathrm{P}$.

$$
P=\left(\begin{array}{lll}
N A & C A & S A \\
p_{11} & p_{12} & p_{13} \\
p_{21} & p_{22} & p_{23} \\
p_{31} & p_{32} & p_{33}
\end{array}\right) \begin{aligned}
& \text { NA } \\
& S A
\end{aligned}
$$

In our study, the two evaluation regimes transparency and opacity are reflected in the transition matrices "T" and "O". As elaborated above, opacity is characterized by a situation where evaluation is relatively difficult, thus rendering decoupling feasible (Meyer \& Rowan, 1977). In contrast, transparency is characterized by relative ease in evaluation, turning decoupling into a largely illegitimate and improbable activity. Specifically, for the sake of simplicity, we assume that in a regime of transparency the probability to moving to state 
“ceremonial adoption" is zero (i.e., $p_{12}=p_{32}=0$ ). Furthermore, because of the risk of social disapproval (delegitimation), we assume that the state "ceremonial adoption" is no longer a valid choice for organizations (i.e., $p_{22}=0$ ).

As an illustration, the following matrices show exemplary transition probabilities for the dynamics of adoption under the conditions of either opacity (transition matrix "O”) or transparency (transition matrix “T”). Note that these matrices formalize extant assumptions of the opacitist and transparentist perspective, respectively (see above).

$$
\begin{aligned}
& O=\left(\begin{array}{lll}
0.7 & 0.2 & 0.1 \\
0.1 & 0.7 & 0.2 \\
0.1 & 0.2 & 0.7
\end{array}\right) \\
& T=\left(\begin{array}{lll}
0.9 & 0.0 & 0.1 \\
0.2 & 0.0 & 0.8 \\
0.0 & 0.0 & 1.0
\end{array}\right)
\end{aligned}
$$

Let us assume that in $\mathrm{t}=0$ the probability that an organization has not yet adopted (neither ceremonially nor substantively) a policy amounts to 100 percent, i.e. $x(0)=\left(\begin{array}{lll}1.0 & 0.0 & 0.0\end{array}\right)$. The distribution of states in $\mathrm{t}=1$ under the regime of opacity is given by:

$$
x(1)=x(0) O^{1}=\left(\begin{array}{lll}
1.0 & 0.0 & 0.0
\end{array}\right)\left(\begin{array}{lll}
0.7 & 0.2 & 0.1 \\
0.1 & 0.7 & 0.2 \\
0.1 & 0.2 & 0.7
\end{array}\right)=\left(\begin{array}{lll}
0.7 & 0.2 & 0.1
\end{array}\right)
$$

After one period (in $t=1$ ), the probability that an organization has adopted the practice substantively is 10 percent (while the probability for ceremonial adoption is 20 percent and the probability of non-adoption is 70 percent). In comparison, in period $t=20$, the distribution is given by the following equation:

$$
x(t)=x(0) O^{T}=\left(\begin{array}{lll}
1.0 & 0.0 & 0.0
\end{array}\right)\left(\begin{array}{lll}
0.7 & 0.2 & 0.1 \\
0.1 & 0.7 & 0.2 \\
0.1 & 0.2 & 0.7
\end{array}\right)^{20}=\left(\begin{array}{ll}
0.25 & 0.40
\end{array}\right.
$$


In the given equation, the probability that an organization has adopted a CR policy substantively is 35 percent ( 25 percent for non-adoption and the remaining 40 percent for ceremonial adoptions). Analogously, the corresponding probabilities under the regime of transparency are given by:

$$
x(t)=x(0) T^{T}=\left(\begin{array}{lll}
1.0 & 0.0 & 0.0
\end{array}\right)\left(\begin{array}{lll}
0.9 & 0.0 & 0.1 \\
0.2 & 0.0 & 0.8 \\
0.0 & 0.0 & 1.0
\end{array}\right)^{20}=\left(\begin{array}{lll}
0.12 & 0.00 & 0.88
\end{array}\right)
$$

Figure 2 depicts the evolution (i.e. time on the x-axis) of the distribution of states under the condition of transparency (left panel) and opacity (right panel) for the first 20 periods. The solid black line reflects the probability of substantive adoption, the gray line the probability of non-adoption, and the dotted black line the probability of ceremonial adoption. As stated above, probability of substantive adoption after $\mathrm{n}$ periods equals the field-level proportion of substantive adoptions after $\mathrm{n}$ periods. Note that the line of non-adoption naturally decreases somewhat steeper in a situation of opacity, because ceremonial adoption represents an additional option for organizations.

Figure 2: State distributions under the regime of transparency vs. opacity
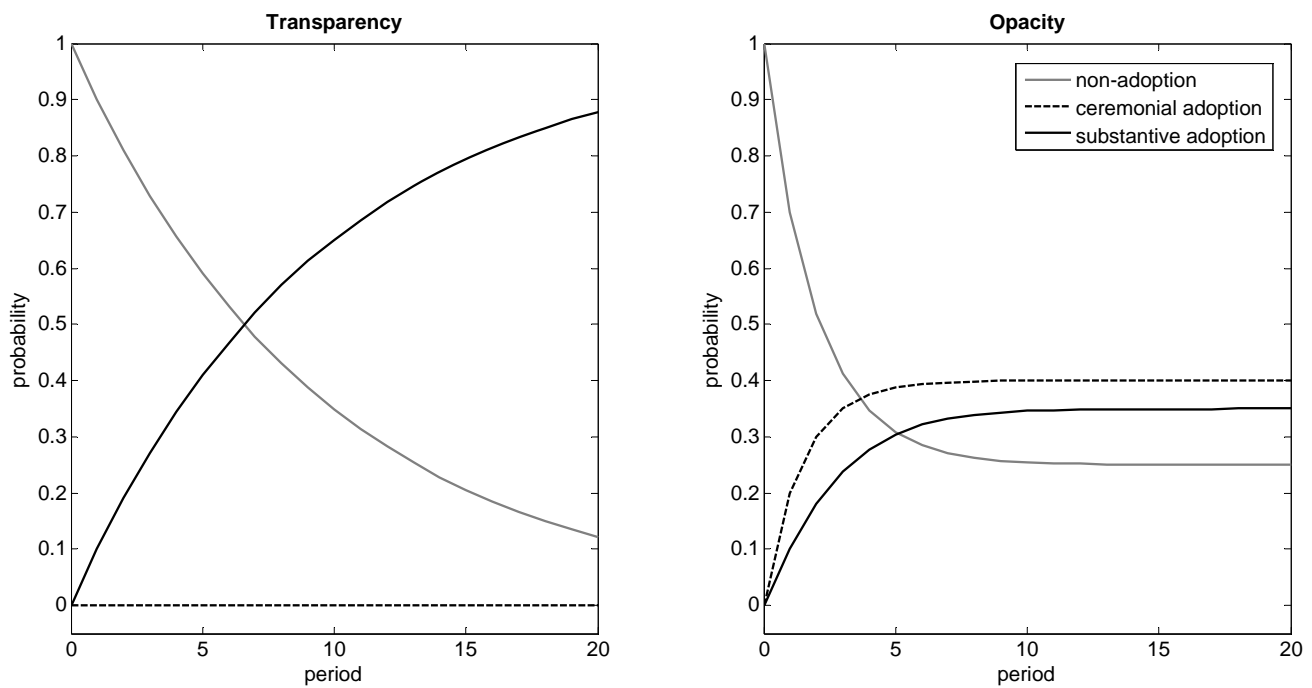
In $\mathrm{t}=0$, given our assumption for $\mathrm{x}(0)$, the probability of ceremonial and substantive adoption equals 0 . The probability of non-adoption is decreasing over time; in a situation of transparency, organizations always adopt a practice substantively; in the situation of opacity, organizations have a higher probability of adopting a practice ceremonially than substantively. Under the regime of opacity, the probability distribution of states remains unchanged after period $t=13$. The system resides in equilibrium. In the regime of transparency, there are still changes. Ultimately, in a situation of transparency, all organizations will adopt the practice substantively. All else equal, given our configuration of the transition matrices for transparency and opacity, the probability that a practice is adopted substantively is always higher under transparency than opacity. Figure 3 reports the probabilities of substantive adoption (y-axis) in a regime of transparency (solid line) vs. a regime of opacity (dotted line) for the first 20 periods (x-axis).

Figure 3: Probability of substantive adoption in a regime of transparency vs. opacity

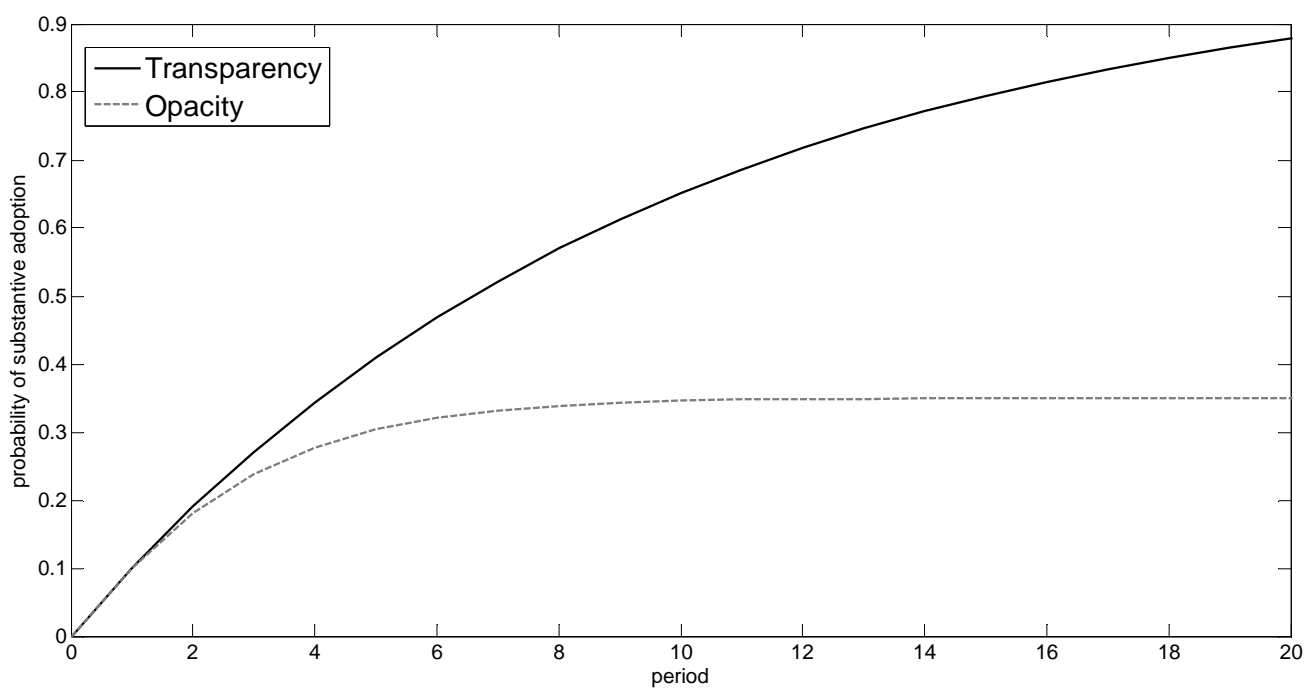

For all periods $t=1$ to $t=20$, transparency results in a higher share of substantive adoption than opacity. For example, by period $t=20$, the probability of substantive adoption in an opacity regime is 35 percent compared to 88 percent in a situation of transparency. 
In sum, if transparency and opacity represent stable regimes (i.e. there are no changes in transition probabilities over time), opacity represents a barrier to substantive adoption. Thus, in order to increase the probability of substantive adoption, one should seek to create transparency, a commendation that is very much in line with the gist of arguments of transparentists (see above). In the following analyses we extend these illustrative findings by exploring whether our results also hold in a situation of regime instability, particularly for situations where opacity (and thus the possibility of decoupling) amounts merely to a transitory phenomenon.

\section{FINDINGS}

\section{Consequences of regime instability}

Further above we demonstrated that opacity impedes substantive adoption, thus providing support for the position of transparentists. In this section, we are particularly interested in exploring the consequences of regime instability, i.e. understanding the implications of a change from one regime to another. How does opacity affect substantive adoption if opacity changes into a regime of transparency? Formally, the state distribution of such a process is given by

$$
x(t)=x(0) O^{R} T^{T-R}
$$

with $\mathrm{R}$ reflecting the number of (initial) periods under a regime of opacity. For the sake of completeness, we also examine the case in which early on (i.e. periods $1,2,3 \ldots \mathrm{R}$ ), decoupling is not possible (the first period is characterized by a regime of transparency), followed by (t-R) periods in which decoupling is possible (characterized by a regime of opacity). $x(t)=x(0) T^{R} O^{T-R}$. Thus, we compare the following four different process sequences: 
Table 1: Possible process sequences

\begin{tabular}{|l|l|l|l|}
\hline & Phase 1 $(\mathrm{t}=1 . . \mathrm{R})$ & Phase 2: $(\mathrm{t}=\mathrm{R}+1 . . \mathrm{T})$ & Literature \\
\hline $\begin{array}{l}\text { Enduring Opacity } \\
(\mathrm{O} / \mathrm{O})\end{array}$ & Opacity & Opacity & $\begin{array}{l}\text { Opacitists, e.g., } \\
\text { Weick, 1995 }\end{array}$ \\
\hline $\begin{array}{l}\text { Enduring } \\
\text { Transparency }(\mathrm{T} / \mathrm{T})\end{array}$ & Transparency & Transparency & $\begin{array}{l}\text { Transparentists, } \\
\text { e.g., Behnam \& MacLean, } \\
2010\end{array}$ \\
\hline $\begin{array}{l}\text { Transitory Opacity } \\
(\mathrm{O} / \mathrm{T})\end{array}$ & Opacity & Transparency & Unexplored \\
\hline $\begin{array}{l}\text { Transitory } \\
\text { Transparency }(\mathrm{T} / \mathrm{O})\end{array}$ & Transparency & Opacity & Unexplored \\
\hline
\end{tabular}

In Figure 4, we display the probability of substantive adoption (y-axis) for the four possible process sequences $(\mathrm{O} / \mathrm{O}, \mathrm{T} / \mathrm{T}, \mathrm{O} / \mathrm{T}, \mathrm{T} / \mathrm{O})$ for the first 20 periods (x-axis). We set the regime change (i.e. a change from opacity and transparency and vice versa) to period $\mathrm{R}=5$.

Figure 4: Share of substantive adoption for different process sequences

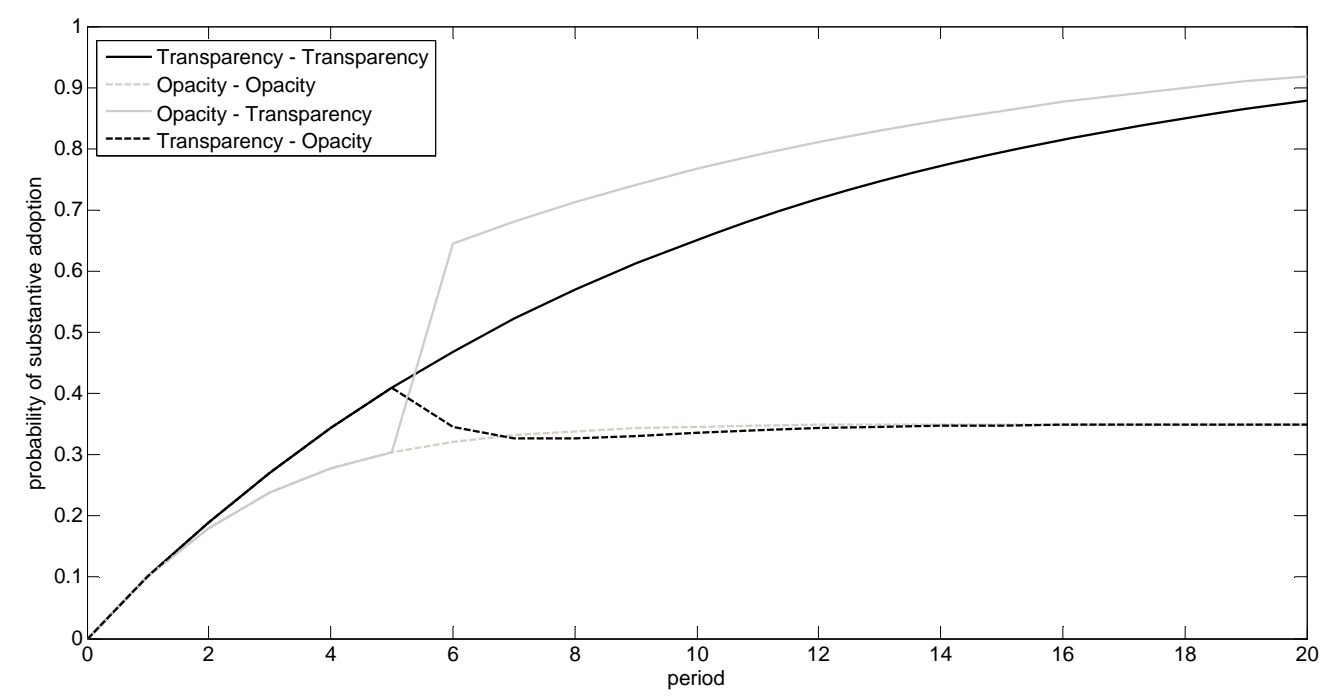

Early on until the "switching point” $\mathrm{R}=5$, transparency (reflected in the solid and dotted dark lines) is associated with higher levels of substantive adoption than opacity (reflected in the solid and dotted gray lines). However, past the switching point, the sequence opacitytransparency (solid gray line), i.e. early opacity (periods prior to period R) and later 
transparency (periods following period R), maximizes the probability of substantive adoption for the periods $\mathrm{t}=\mathrm{R}$ to $\mathrm{t}=20$. In other words, if opacity (and thus decoupling) amounts only to a transitory phenomenon, initial opacity maximizes substantive adoptions and "outperforms" the share of substantive adoptions that would accrue under the other three process sequences.

\section{Identification of boundary conditions: When does OT do better than TT?}

Obviously, the finding that the process pattern O/T (transitory opacity) maximizes substantive adoption is dependent on specific transition probabilities in the transition matrices $\mathrm{T}$ and $\mathrm{O}$. In order to examine how robust our results are to changing transition probabilities in the transparency matrix, we keep constant transition probabilities for the opacity matrix (further below we also explore robustness in respect to changes in the opacity matrix). In our example above, the transition probabilities under the regime of transparency vs. opacity were given by:

$$
T=\left(\begin{array}{lll}
0.9 & 0.0 & 0.1 \\
0.2 & 0.0 & 0.8 \\
0.0 & 0.0 & 1.0
\end{array}\right) \text { and } O=\left(\begin{array}{ccc}
0.7 & 0.2 & 0.1 \\
0.1 & 0.7 & 0.2 \\
0.1 & 0.2 & 0.7
\end{array}\right)
$$

In the following analysis, we explore all possible configurations of $\mathrm{T}$ :

$$
T\left(t_{13}, t_{23}, t_{33}\right)=\left(\begin{array}{lll}
1-t_{13} & 0.0 & t_{13} \\
1-t_{23} & 0.0 & t_{23} \\
1-t_{33} & 0.0 & t_{33}
\end{array}\right)
$$

Recall that a regime of transparency assumes that ceremonial adoption becomes an unattractive $\left(p_{12}=p_{32}=0\right)$ and instable state $\left(p_{22}=0\right)$; therefore, all entries in the transition matrix's center column amount to zero. With this assumption, all possible configurations of $\mathrm{T}$ can be described by the three variables $t_{13}, t_{23}$, and $t_{33}$.

In Figure 5, we report which of the four process sequences (i.e. T/T, O/O, O/T, and $\mathrm{T} / \mathrm{O}$ ) result in the highest probability of substantive adoption (averaged over periods $\mathrm{t}=1$ to $\mathrm{t}=20$ ). For each panel (reflecting exemplary values for $t_{23}, 0.1,0.5$, and 0.9 ), we compute the share of substantive adoption for the four different process sequences. Each point in the panel reflects a different combination of $t_{13}$ (x-axis) and $t_{33}$ (y-axis). A point is colored black if the 
sequence T/T outperforms all other sequences; we use dark gray to indicate that the sequence $\mathrm{O} / \mathrm{O}$ leads to the highest share of substantive adoption. White and light gray points indicate that the sequence $\mathrm{T} / \mathrm{O}$ and $\mathrm{O} / \mathrm{T}$ are optimal, respectively.

\section{Figure 5: Boundary conditions under which each of the four process sequences} maximize the share of substantive adoptions
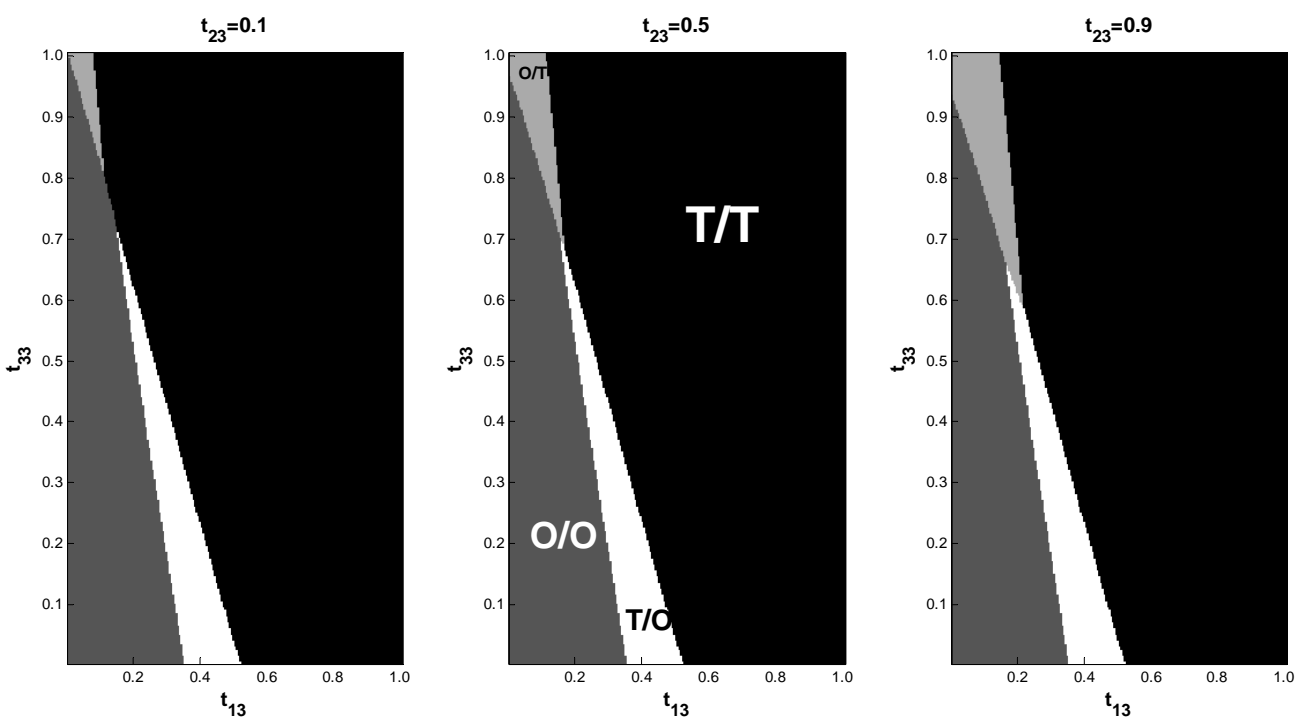

In all three panels, we observe some general patterns: First, for most combinations of $t_{13}, t_{23}, t_{33}$, enduring transparency (i.e. $\mathrm{T} / \mathrm{T}$ ) leads to highest shares of substantive adoption. Second, transitory opacity (i.e. $\mathrm{O} / \mathrm{T}$ ) is the optimal sequence (i.e. maximizes the probability of substantive adoption) if: $t_{13}$ is low and $t_{33}$ is high. In other words, non-adopters must have a low probability of turning into substantive adopters under the regime of transparency, in particular compared to the corresponding probability under a regime of opacity. Furthermore, transparency must stabilize the state of substantive adoption: the probability $t_{33}$ must be higher (but not necessarily equaling 1.0) than the corresponding probability $o_{33}$. Third, enduring opacity (i.e. $\mathrm{O} / \mathrm{O}$ ) is optimal for combinations of low $t_{13}$ and for the full range of $t_{33}$, i.e., even if in a regime of transparency non-adopters have a low probability to become substantive adopters and at the same time have a high probability of abandoning substantive adoptions. Finally, transitory transparency (i.e. T/O) is optimal for 
medium to low high levels of $t_{33}$. In other words, compared to opacity, only if transparency increases the probability of abandoning substantive adoptions (which is a rather unrealistic scenario), transitory transparency turns into the optimal sequence.

If we compare the three panels (in Figure 5), we can observe that-although the different areas differ in size - the general pattern is fairly stable. Interestingly, even with low $t_{23}=0.1$, i.e. if ceremonial adopters move to substantive adoption with a probability of only 10 percent (and there is a 90 percent probability that a ceremonial adopter turns into a nonadopter), there are still $t_{13} / t_{33}$ combinations for which transitory opacity maximizes the probability for substantive adoption. Overall, Figure 5 helps identifying those transition matrices $\mathrm{T}$ for which any of the four process pattern is optimal, i.e. maximizes the share of substantive adoptions (given a particular transition matrix O).

We also tested whether the key finding that under specific $t_{13} / t_{33}$ combinations OT maximizes the share of substantive adoptions is indifferent to changes in the opacity matrix (in the previous analyses we kept the transition probabilities of the opacity matrix constant). To describe the transition matrix $\mathrm{O}$, we need at least six independent variables (compared to just three for the transition matrix T). Since the entire solution space grows exponentially in the number in the number of independent variables, a comprehensive exploration of all possible solutions is difficult. We therefore checked the robustness of our findings by choosing a transition matrix $\mathrm{T}$ for which the sequence $\mathrm{O} / \mathrm{T}$ is optimal holding $\mathrm{T}$ constant; we then created 10,000 random matrixes $\mathrm{O}$ and tracked in how many cases the sequence O/T has been optimal, when compared to the other three possible process sequences. For the case of $\mathrm{O}$ being a random matrix, we find that $\mathrm{O} / \mathrm{T}$ maximizes the probability of substantive adoption with a probability of 91 percent. This means that the superiority of $\mathrm{O} / \mathrm{T}$ holds for a wide range of possible opacity matrices. 


\section{Different switching points and their endogenization}

Our prior analyses have been based on the assumption that for the process sequence $\mathrm{O} / \mathrm{T}$ and $\mathrm{T} / \mathrm{O}$ a regime switch takes place at $\mathrm{R}=5$ out of 20 periods. In figure 6 , we display the average probability of substantive adoption (y-axis, averaged over all 20 periods) for different switching points, ranging from $\mathrm{R}=0$ to $\mathrm{R}=20$.

\section{Figure 6: Substantive adoption for different switching points $\mathbf{R}$}

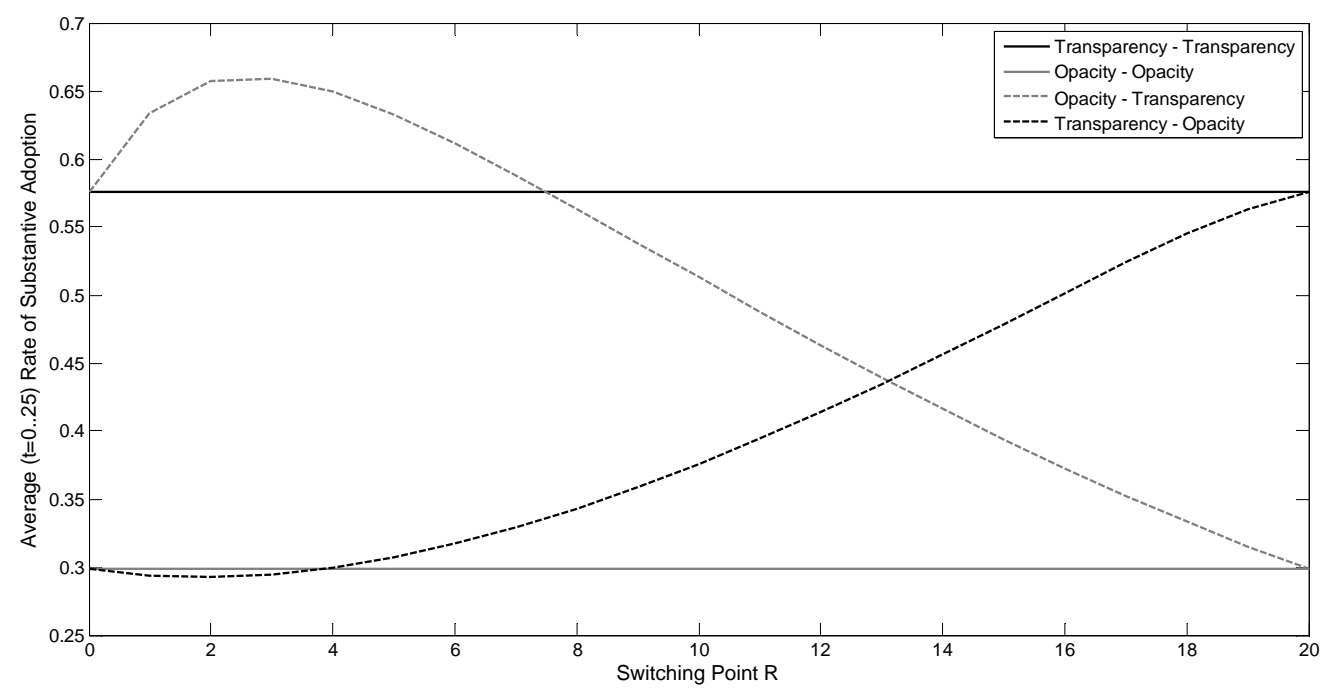

As depicted in Figure 6, for sequence $\mathrm{O} / \mathrm{T}$ the optimal switching point is $\mathrm{R}=3$, i.e. comparably early in the proliferation process of a CR policy. For all Rs between 1 and 7, O/T leads to higher shares of substantive adoption than the process sequence T/T (as well as O/O). Importantly, in cases where opacity turns into transparency only after 8 periods, there are no benefits stemming from transitory opacity; instead, the probability of substantive adoption for periods later than $\mathrm{R}=8$ drops to the level of $\mathrm{O} / \mathrm{O}$. In summary, this analysis clarifies that the timing of the switching point is important. It suggests that the benefits of process sequence $\mathrm{O} / \mathrm{T}$ are most pronounced if opacity constitutes only a very short, temporal phenomenon. If the transition to transparency "comes too late”, O/T reduces the share of substantive adoption and any benefits disappear. 
So far, we modeled the switching point as an exogenous factor. However, in real-life dynamics of CR practice adoptions, this switching point can be endogenous to the process dynamics themselves, i.e. it depends on the development and distribution of adoptions in a given industry. For instance, under the condition of opacity, if too many organizations adopt a CR policy ceremonially and at least a few organizations have adopted substantively, we would expect that as soon substantive adopters become aware of such differences they have an interest to create a regime of transparency, in order to enable constituents to distinguish between "true” adopters and mere "free-riders" (Barnett \& King, 2008). In order to capture the dynamics of such processes, we endogenize the switching point $\mathrm{R}$ by defining it as a function of the share of substantive adoptions to overall adoptions.

Assuming an endogenous switching point raises the question how the ratio between all adopters and substantive adopters depends on the configuration of the opacity matrix (recall that with transparency, ceremonial adoption is not a viable state). Therefore, let us assume that the transition matrix $\mathrm{O}$ is given by:

$$
O\left(o_{13}, o_{23}\right)=\left(\begin{array}{ccc}
0.7 & 1-o_{13} & o_{13} \\
1-o_{23} & 0.7 & o_{23} \\
0.1 & 0.2 & 0.7
\end{array}\right)
$$

In Figure 7, we report the share of substantive adopters (of all adopters) in $t=R=5$ as a function of $o_{13}$ and $o_{23}$ (i.e. the probability that non-adopters and ceremonial adopters move to substantive adoption). The different lines reflect different values of this share, ranging from 0.15 to 0.6 . 


\section{Figure 7: Share substantive adopters of all adopters}

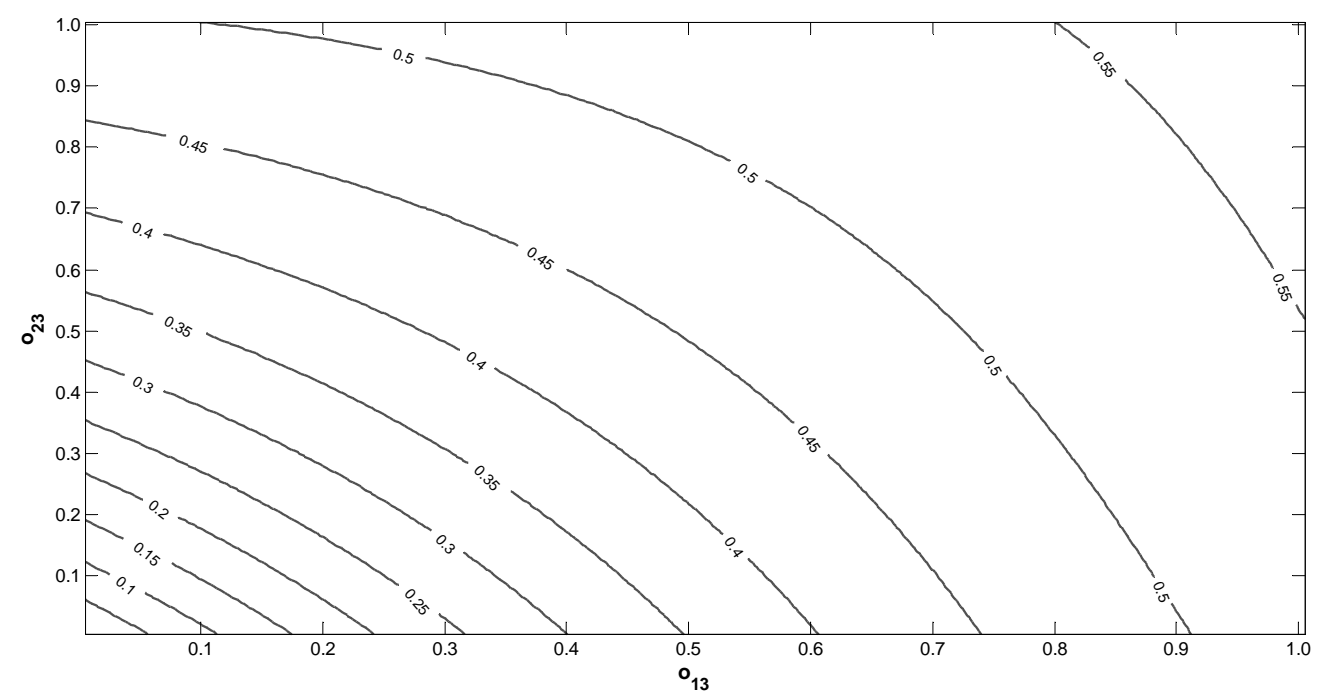

Depending on our choices for $o_{13}$ and $o_{23}$, the share of substantive adopters in period $\mathrm{t}=\mathrm{R}=5$ might be quite different. This has important implications for cases in which the regime switch is endogenous, i.e. a function of this share. For example, if we assume that in order to trigger this switch, the share must be larger 0.4 , then, only combinations of $o_{13}$ and $o_{23}$ that are above the curve connecting $o_{13}=0.6$ (see x-axis) and $o_{23}=0.7$ (see y-axis) will experience a regime switch (see curve line annotated with 0.4); combinations below this curve will never experience a move from opacity to transparency. This analysis thus suggests that if the switching point of a regime change is endogenous, the switch in regimes may occur earlier or later (or in the worst case, depending on the switching rule, may not happen at all). In figure 8, we repeated the analysis of Figure 5 yet incorporated an endogenous switch: While in Figure 5 the switch has been set exogenously and occurred always in period $t=R=5$, the switch now occurs only if the share substantive adopters/all adopters exceeds 40 percent. Note that we use the value of 40 percent merely as an example. The actual switching rule may also be triggered by a share of 10 percent or 60 percent. Indeed, the rule may be based on an entirely different trigger that does not involve the share of substantive adopters. The purpose of this 
analysis is simply to explore how endogenizing the regime switch may affect our key finding that transitory opacity maximizes the share of substantive adoptions.

Figure 8: Boundary conditions in consideration of an endogenous switch
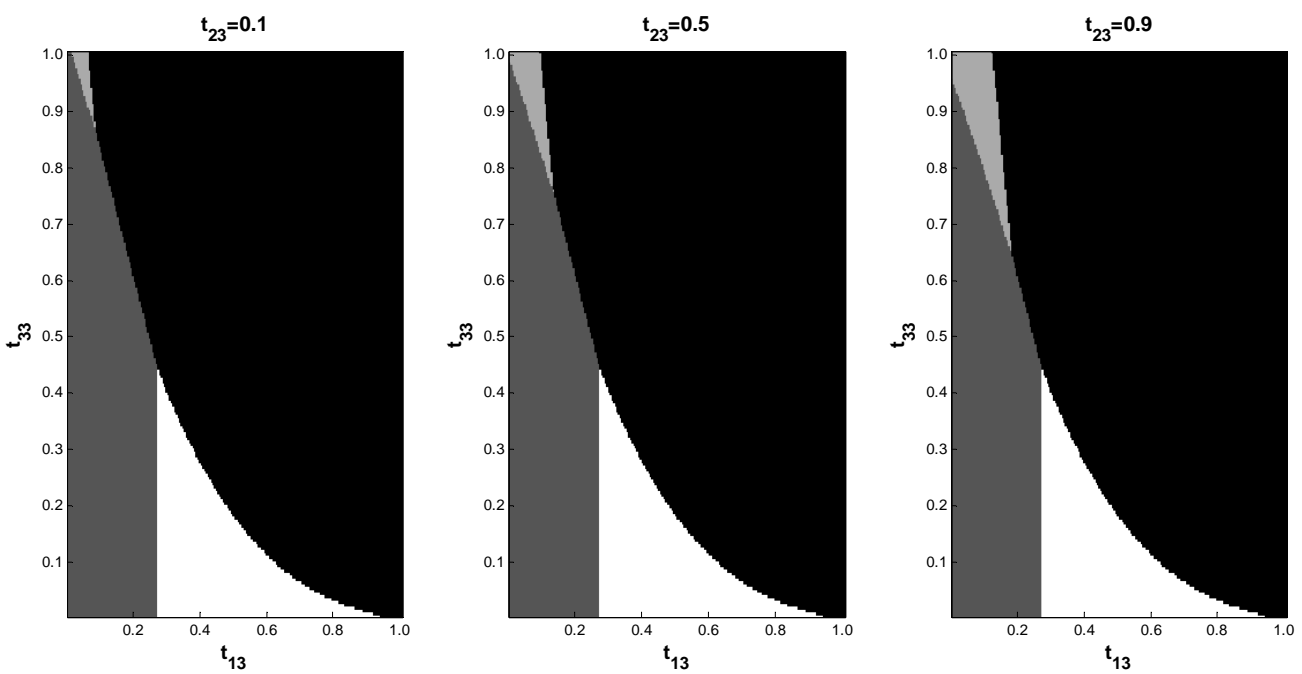

In sum, endogenizing the switch changes the shapes of the areas for which the four different process sequences are optimal, i.e. maximize the share of substantive adoption; however, the general pattern, in particular under what conditions transitory opacity (process pattern $\mathrm{O} / \mathrm{T}$ ) is optimal, remains by and large unaffected (see Figure 5).

\section{DISCUSSION AND CONCLUSION}

Prior research on decoupling and practice adoption generated mixed evidence on the role of opacity in promoting substantive adoption. One set of scholars suggests that opacity, understood as the relative difficulty or impossibility of evaluation, may promote substantive adoption (e.g., Weick, 1995). Yet, another camp of scholars considers opacity as a barrier to substantive adoption (e.g., Behnam \& MacLean, 2011). In our study, we identify and reconcile theoretical tensions and inconsistencies underlying the opacitist and the transparentist perspective. Although both scholarly communities have been partly "right" by stressing the significance of either transparency or opacity, previous works failed to take into account the role of sequence and endogeneity effects in shaping adoption outcomes. We 
address this deficiency by employing an explicit proccessual perspective which allows us to build an internally consistent theory of practice adoption and coupling processes in the realm of CR (see Poole \& van de Ven, 1989).

Specifically, we theorize the possibility of changes in evaluation regimes. That is, we model process sequences that include not only enduring transparency or enduring opacity but both transparency and opacity. We identify the boundary conditions (i.e. the set of transition probabilities) under which any of the four possible process patterns of transparency and opacity (e.g. T/T, O/T, T/O, or $\mathrm{O} / \mathrm{O}$ ) lead to the highest share of substantive adoptions. In this paper, we have been particularly interested in identifying conditions under which transitory opacity (i.e. the process pattern $\mathrm{O} / \mathrm{T}$ ) promotes substantive adoption. We find that $\mathrm{O} / \mathrm{T}$ enhances substantive adoption for cases combining a relatively low transition probability from non-adoption to substantive adoption and a high probability that substantive adoption remains stable. In other words, under these conditions transitory opacity maximizes substantive adoptions within a given field, that is, the process sequence $\mathrm{O} / \mathrm{T}$ leads to a higher share of substantive adoption than any of the other three process sequences ( $T / T, T / O$, or $\mathrm{O} / \mathrm{O}$ ). Importantly, indentified conditions are quite realistic for the realm of $\mathrm{CR}$, given the difficulty to instantly translate CR policies into practice (Boiral, 2007), and the impossibility to recede from a once established standard of substantive adoption (Christensen et al., 2011). Hence, transitory opacity amounts to an important but largely overlooked path to global sustainability. In the following, we further outline the paper's two major theoretical contributions.

\section{In defense of organizational hypocrisy: Bad, but not for good}

We contribute to the broader literature on CR and contemporary efforts to institutionalize CR as a means to tackle regulative voids in global governance (Gilbert et al., 2007; Scherer and Palazzo, 2007). Our analysis suggests that the dominant (and often implicit) notion that a 
situation of transparency invariably furthers the cause of global sustainability may be wrong. Neither is the opposing view fully correct, i.e. the argument that opacity and the absence of sanctions nurture substantive adoption. It is only in the blending of transparentist and opacitist views that we reveal a novel and promising path to institutionalize of CR.

With good cause, both academics and practitioners disapprove of the ceremonial adoption of CR and urge organizations to 'walk the talk', that is, to quickly promote the substantive integration of CR initiatives. By studying adoption patterns in a dynamic perspective, however, we gain an enhanced understanding of adoption processes and find that under specific boundary conditions the process sequence O/T (initial opacity followed by transparency) maximizes the share of substantive adoptions. In contrast, an initially more rigorous stance toward accountability and social control slows down or even stalls substantive adoption, as evidenced by lower shares of substantive adoption under the process sequence of enduring transparency (T/T). Of course, the "lowest common denominator" (Sethi, 2002) is conducive to opportunism and adverse selection, and scholars rightly question the merit of low entry barriers for industry self-regulation (King \& Lenox, 2000; Lenox \& Nash, 2003). Yet, even the most hypocritical adoption of CR policies might prove instable and yield longterm institutional consequences, not only because of instability of decoupling within a single organization (typified by the notion of “moral entrapment”), but also because of sequence and endogeneity effects at the institutional field level. Hence, given that initial opacity and unsanctioned decoupling constitute a viable way to global sustainability, both scholars and activists should not unconditionally sanction organizations for decoupling, but rather tolerate a transformation stage that allows ceremonial adoptions to reach a "critical mass" i.e. a switching point that triggers a regime change that ultimately heralds the demise of ceremonial adoption. Importantly, our findings suggest that this switching point needs to occur early; otherwise the benefits of initial opacity are lost. Overall, having explored the self-reinforcing 
processes and endogeneity effects in adoption sequences we hope to have contributed to a better understanding for the pivotal boundary conditions and mechanisms underlying a successful deepening and institutionalization of CR.

\section{Rethinking evaluation and adoption as mutually constitutive phenomena}

Recent studies have emphasized the need to rethink the assumption that opacity and decoupling constitute enduring states and examined the antecedents and consequences of coupling processes, i.e. the gradual alignment of structure and actual activity (Christensen et al., 2011; Haack et al., 2012; Hallett, 2010; Tilcsik, 2010). This paper contributes to the development of the institutional theory concept of decoupling and extant notions of coupling and entrapment processes as follows: First, we formalize extant metaphorical theorizing of increasing demands for transparency (e.g. "walk the talk”, “raise the bar”) by modeling shifting demands as a change in evaluation regimes in a Markov chain process. This approach allows us to formalize how a specific evaluation regime (opacity/transparency) affects the behavioral disposition of organizations to adopt a policy (non-adoption/ceremonial adoption/substantive adoption). Importantly, our study reveals that transitory opacity can engender a rise in the share of substantive adoption even if in a regime of transparency the probability to move from ceremonial adoption to substantive adoption is very low (e.g. if $t_{23}$ $=0.1$, see Figure 5). Thus, choosing the path of moral entrapment (which, formally speaking, is represented by a high transition probability $t_{23}$ ) constitutes a possible, but not a necessary condition to advance the institutionalization of CR.

Second, we explore the implications of making the timing of a regime change contingent on a specific field-level proportion of substantive adoption (or on any other switching rule). Given that transition probabilities also depend on the type of evaluation (opacity or transparency), adoption and evaluation are mutually constitutive. Therefore, the here suggested conceptualization of CR institutionalization resembles a path-dependent 
process that leads into a self-reinforcing rise in the share of substantive adoptions (lock-in, see, e.g., Vergne \& Durand, 2010). This process is not driven by moral entrapment (the notion that ceremonial adoption is eventually followed by substantive adoption, at the level of a single organization) but by changes in the stability of non-adoption and substantive adoption, due to a field-level regime change from opacity to transparency. Thus, modeling adoption behavior and evaluation as dynamic and mutually constitutive uncovers a path-dependent mechanism that goes beyond organizational commitment and entrapment effects and helps reconciling the bias towards stasis in extant approaches of decoupling and practice adoption. 


\section{REFERENCES}

Abbott, A. (1990). A primer on sequence methods. Organization Science, 1, 375-392.

Abrahamson, E., \& Fairchild, G. (1999). Management fashion: Lifecycles, triggers, and collective learning processes. Administrative Science Quarterly, 44, 708-740.

Ansari, S. M., Fiss, P. C., \& Zajac, E. J. (2010). Made to fit: How practices vary as they diffuse. Academy of Management Review, 35, 67-92.

Aravind, D., \& Christmann, P. (2011). Decoupling of standard implementation from certification: Does quality of ISO 14001 implementation affect facilities' environmental performance? Business Ethics Quarterly, 21, 73-102.

Barnett, M. L., \& King, A. A. (2008). Good fences make good neighbors: A longitudinal analysis of an industry self-regulatory institution. The Academy of Management Journal, 51, 1150-1170.

Behnam, M., \& MacLean, T. L. (2011). Where is the accountability in international accountability standards? A decoupling perspective. Business Ethics Quarterly, 21, 4572.

Berger, P. L., \& Luckmann, T. (1967). The social construction of reality: A treatise in the sociology of knowledge. New York: Anchor.

Boiral, O. (2007). Corporate greening through ISO 14001: A rational myth? Organization Science, 18, 127-146.

Boxenbaum, E., \& Jonsson, S. (2008). Isomorphism, diffusion, and decoupling. In R. Greenwood, C. Oliver, K. Sahlin, \& R. Suddaby (Eds.), The Sage handbook of organizational institutionalism (pp. 299-323). London: Sage.

Bromley, P., \& Powell W. W. (2012). From smoke and mirrors to walking the talk: Decoupling in the Contemporary World, The Academy of Management Annals, DOI:10.1080/19416520.2012.684462.

Brunsson, N. (1989): The organization of hypocrisy. Boston: John Wiley \& Sons

Christensen, L. T., Morsing, M., and Thyssen, O. (2011). The polyphony of corporate social responsibility: Deconstructing transparency and accountability and opening for identity and hypocrisy. In G. Cheney, S. May, \& D. Munshi (Eds.), The handbook of communication ethics (pp. 457-473). New York: Routledge.

Christmann, P., \& Taylor, G. (2006). Firm self-regulation through international certifiable standards: determinants of symbolic versus substantive implementation. Journal of International Business Studies, 37, 863-878.

Colyvas, J. A., \& Jonsson, S. (2011). Ubiquity and legitimacy: Disentangling diffusion and institutionalization. Sociological Theory, 29, 27-53. 
Delmas, M., \& Montes-Sancho, M. J. (2011). An institutional perspective on the diffusion of international management system standards: The case of the environmental management standard ISO 14001. Business Ethics Quarterly, 21, 103-132.

den Hond, F., \& de Bakker, F. G. A. (2007). Ideologically motivated activism: How activist groups influence corporate social change activities. Academy of Management Review, 32, 901-924.

Diekmann, A., Przepiorka, W., \& Rauhut, H. (2011). Die Präventivwirkung des Nichtwissens im Experiment. Zeitschrift für Soziologie 40, 74-84.

Kennedy, M. T., \& Fiss, P. 2009. Institutionalization, framing, and diffusion: The logic of TQM adoption and implementation decisions among U.S. hospitals. Academy of Management Journal, 52, 897-918.

Gilbert, D. U., Rasche, A., \& Waddock, S. (2011). Accountability in a global economy: The emergence of international accountability standards. Business Ethics Quarterly, 21, 2344.

Haack, P., Schoeneborn, D., \& Wickert, C. (2012). Talking the talk, moral entrapment, creeping commitment? Exploring narrative dynamics in corporate responsibility standardization'. Organization Studies, 33, 5/6.

Hallett, T. (2010). The myth incarnate: Recoupling processes, turmoil, and inhabited institutions in an urban elementary school. American Sociological Review, 75, 52-74.

Humphreys, M., \& Brown, A. D. (2008). An analysis of corporate social responsibility at credit line: A narrative approach. Journal of Business Ethics, 80, 403-418.

Jamali, D. (2010). MNCs and international accountability standards through an institutional lens: Evidence of symbolic conformity or decoupling. Journal of Business Ethics, 95, 617-640.

Jonsson, S., Greve, H., \& Fujiwara-Greve, T. (2009). Undeserved loss: The spread of legitimacy loss to innocent organizations in response to reported corporate deviance. Administrative Science Quarterly, 54, 195-228.

King, A. A., \& Lenox, M. J. (2000). Industry self-regulation without sanctions: The chemical industry’s responsible care program. Academy of Management Journal, 43, 698-716.

Langley, A. (1999). Strategies for theorizing form process data. Academy of Management Review, 24, 4, 691-710.

Laufer, W. S. (2003). Social accountability and corporate greenwashing. Journal of Business Ethics, 43, 253-261.

Lenox, M. J., \& Nash, J. 2003. Industry self-regulation and adverse selection: A comparison across four trade associations programs. Business Strategy and Environment, 12, 343356. 
Long, B. S., \& Driscoll, C. (2008). Codes of ethics and the pursuit of organizational legitimacy: Theoretical and empirical contributions. Journal of Business Ethics, 77, 173-189.

Lounsbury, M. (2001). Institutional sources of practice variation: Staffing college and university recycling programs. Administrative Science Quarterly, 46, 29-56.

MacLean, T. L., \& Behnam, M. (2010). The dangers of decoupling: The relationship between compliance programs, legitimacy perceptions, and institutionalized misconduct. Academy Of Management Journal, 53, 1499-1520.

March, J. C. (1995). A primer on decision making: How decision happen. New York: Free Press.

March, J. C., \& March, J. G. (1977). Almost random careers. The Winconsin school superintendency, 1940-1972. Administrative Science Quarterly, 22, 377-409.

Meyer, J. W., \& Rowan, B. (1977). Institutionalized organizations: Formal structure as myth and ceremony. American Journal of Sociology, 83, 340-363.

Okhuysen, G., \& Bonardi, J.P. (2011). The challenges of theory building through the combination of lenses. Academy of Management Review. January: 6-12, From the Editor section.

Pentland, B. T. (2003). Sequential variety in work processes. Organization Science, 14, 528540.

Pentland, B. T. Hærem T., \& Hillison, D. (2010). Comparing organizational routines as recurrent patterns of action. Organization Studies, 31, 917-940.

Poole, M. S., \& and Van de Ven, A. H. (1989). Using paradox to build organization and management theories. Academy of Management Review, 15, 3: 562-578.

Røvik, K. A. (2011). From fashion to virus: An alternative theory of organizations' handling of management ideas. Organization Studies, 32, 631-653.

Scherer, A. G., \& Palazzo, G. (2007). Toward a political conception of corporate responsibility: Business and society seen from a Habermasian perspective. Academy of Management Review, 32, 1096-1120.

Schneiberg, M., \& Clemens, E. S. (2006). The typical tools for the job: Research strategies in institutional analysis. Sociological Theory, 24, 195-227.

Scott, W. R. (2008). Institutions and organizations: Ideas and interests, $3^{\text {nd }}$ edition. Thousand Oaks, CA: Sage.

Suddaby, R., \& Greenwood, R. (2009). Methodological issues in researching institutional change. In D. Buchanan, \& A. Bryman (Eds.), The Sage handbook of organizational research methods (pp. 177-195). London: Sage.

Sydow, J., Schreyögg, G., \& Koch, J. (2009). Organizational path dependence: Opening the black box. Academy of Management Review, 34, 689-709. 
Tenbrunsel, A. E., \& Messick, D. M. (1999). Sanctioning systems, decision frames, and cooperation. Administrative Science Quarterly, 44, 684-707.

Tilcsik, A. (2010). From ritual to reality: Demography, ideology, and decoupling in a postcommunist government agency. Academy of Management Journal, 53, 1474-1498.

Tolbert, P. S., \& Zucker, L. G. (1996). The institutionalization of institutional theory. In S. R. Clegg, C. Hardy, \& W. R. Nord (Eds.), Handbook of organization studies (pp. 175190). Sage: London.

Weick, K. E. (1976). Educational organizations as loosely coupled system. Administrative Science Quarterly, 21, 1-19.

Weick, K. E. (1995). Sensemaking in organizations. Thousand Oaks: Sage.

Vergne, J. P., \& Durand, R. (2010). The missing link between the theory and empirics of path dependence: Conceptual clarification, testability issue, methodological implications, Journal of Management Studies, 47, 736-759

Zyglidopoulos S., \& Fleming P. (2011). Corporate accountability and the politics of visibility in late modernity. Organization, 18, 691-706. 